$11-1995$

\title{
Explanatory Practice in Family Studies
}

Jetse Sprey

Cleveland State University, j.sprey@csuohio.edu

Follow this and additional works at: https://engagedscholarship.csuohio.edu/clsoc_crim_facpub

Part of the Family, Life Course, and Society Commons

How does access to this work benefit you? Let us know!

\section{Original Citation}

Sprey, J. (1995). Explanatory practice in family studies. Journal Of Marriage \& Family, 57(4), 867-878.

\section{Repository Citation}

Sprey, Jetse, "Explanatory Practice in Family Studies" (1995). Sociology \& Criminology Faculty Publications. 37.

https://engagedscholarship.csuohio.edu/clsoc_crim_facpub/37

This Article is brought to you for free and open access by the Sociology \& Criminology Department at EngagedScholarship@CSU. It has been accepted for inclusion in Sociology \& Criminology Faculty Publications by an authorized administrator of EngagedScholarship@CSU. For more information, please contact library.es@csuohio.edu. 


\section{Jetse SPREY Cleveland State University
Explanatory Practice in Family Studies

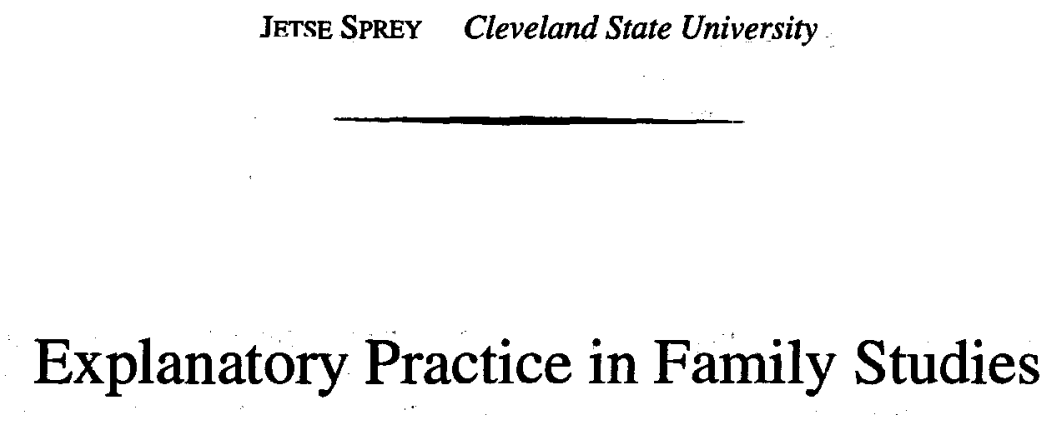

This article makes a case for a more flexible and realistic explanatory practice in the family field. It discusses current descriptive, conceptual, and theoretical approaches. Furthermore, attention is paid to the phenomenon of explanation itself, to its predictive power and to the logical context of its questions and answers. In addition to the use of selected sources from the realm of family studies, the presentation adopts ideas from the domains of the philosophy of science, mathematics, and related social sciences.

Now faith is the substance of things hoped for, the evidence of things not seen.

Hebrews 11:1

The question "What is an explanation?" rarely is asked by family scholars. Despite this, their collective explanatory endeavor seems neither haphazard nor purely idiosyncratic. Explaining something, on the whole, tends to be seen as different from trying to understand it, the latter offering a "deeper" but also a less rigorous type of knowing. Our explanatory practice reflects a pecking order in which theorizing outranks conceptual analysis and "mere" description. Usually, the last two approaches are not seen to be explanatory at all.

Department of Sociology, Cleveland State University, Cleveland, $\mathrm{OH} 44115$. Correspondence address: 2211 Westminster Road, Cleveland Heights, OH 44118.

Key Words: conceptualization, description, explanation, methodology, prediction, theory.
A few quotes from recent work by established family scholars may serve to illustrate the foregoing. First, two statements lifted from a chapter titled "Family Power" by Szinovacz (1987): "It is only when we attempt to explain or predict power that a dynamic conceptualization and careful investigation of 'powering' become necessary" (p. 656) and "For a descriptive analysis of power, a static model of control may suffice, but an explanation of power relations must reflect the complexity and dynamics of ongoing 'powering' processes" (p. 659). Explanation, in these statements, entails both prediction and dynamic conceptualization, in contrast to a static descriptive analysis.

A second example, from an essay on the history of theorizing in the family field, is equally telling: "Theory is explanation; it answers the questions how, why, under what conditions. It is not description, myth or legend, or ideology" (Adams \& Steinmetz, 1993, p. 75). Here, explaining appears as an integral aspect of theorizing and is linked to specific modes of questioning.

Contrary to the above views, I see explaining as a sense-making activity that, depending on its specific context, can be descriptive, conceptual, or theoretical. In other words, "what an explanation. is, or can be or ought to be, depends in any given case upon its context and upon the character of the inquiry in which it occurs" (Gallie, 1968, p. 20).

My stance essentially reflects an image of marriage and family process as one of collective survival and potential prospering, under complex and basically uncertain conditions. Explanations of marriage and family living - and of the institutional arrangements that fashion reproduction and 
the care of offspring in our society - thus must be sought at the crossroads of several scholarly fields. This has led to a discipline marked by a heterogeneity of focus, differing and, at times, conflicting interests, and a discourse characterized by dissensus as well as consensus (Sprey, 1990). This, in turn, suggests an explanatory enterprise that allows for the management-not necessarily the resolution-of the intellectual and ideological disputes that are likely to continue as an integral aspect of family studies.

This essay is about explaining as a process and as the outcomes of that process. It is not meant to be a purely theoretical effort, nor does it aim to present specific recipes for the explanation of phenomena and events. I intend to make a case rather than to prove one. In line with this, my argument is fashioned by "following the common scientific practice of the persuasive use of citations" (Kellert, 1993, p. xii). After a brief treatment of explanation per se-especially the logic of its questioning and its predictive power-description, conceptualization, and theorizing are dealt with in turn as explanatory strategies in the family field.

\section{ON EXPLANATION}

An explanation is a statement designed to make sense of something that, so far, remains poorly understood and inadequately accounted for. It is the answer to a question and, in that capacity, must accomplish two things. First, the curiosity of those asking the question should be satisfied. Secondly, especially in scholarly domains of inquiry, the explanation should provide credible and relevant information.

Pragmatically speaking, one could argue that an explanation has served its purpose when the curiosity of its questioners is satisfied. Decades ago the physicist P. W. Bridgman (1928) wrote that "examination will show that the essence of an explanation consists in reducing a situation to elements with which we are so familiar that we accept them as a matter of course, so that our curiosity rests" (p. 37). Some contemporary scholars reject this view as too simplistic (cf. Salmon, 1984), and their point is well taken. Bridgman's comment, however, touches on an intrinsic aspect of all explaining, namely its relativity. In his important book The Scientific Image, the philosopher Van Fraassen (1980) put it this way:

Being an explanation is essentially relative, for an explanation is an answer. (In just that sense, being a daughter is something relative: Every woman is a daughter, and every daughter is a woman, yet being a daughter is not the same as being a woman.) Since an explanation is an answer, it is evaluated vis-à-vis a question, which is a request for information. But exactly what is requested ... differs from context to context. (p. 156)

In other words, our explanations to children differ from those to adults, those to the ignorant differ from those to the experts, and those to strangers differ from those to friends.

Of course, the "ignorant" and children are unlikely consumers of the explanatory contributions of family scholars, whose audience consists of their professional colleagues, clinicians, informed policy makers, and a relatively select segment of those who exist in marriages and families. One must ask, therefore, how separate is this audience from the one studied by scholars, guided by clinicians, and manipulated by policy makers? In this essay the line between what family scholars do and what their "subjects" do is a dotted one. In fact, a good number of the quotations offered in this article echo the explanatory practices of those who live the realities of our subject matter's world. It is here, I believe, that a reflection on the state of explanatory practice in the family field differs fundamentally from that in either physics or biology.

What further complicates attempts to understand the nature of explaining in all scholarly disciplines is the fact that explanations serve not merely as answers but also as assertions. They present claims one wants to have accepted as valid, relevant, and of importance to the state of knowledge in and, perhaps, beyond one's field. One desires more than just to satisfy one's own curiosity, and this requires a set of shared conventions, an established "methodology," and a culture in which such standards are recognized and sanctioned.

\section{The Status Quo}

Earlier cited perceptions of explanation in our field illustrate, perhaps unwittingly, that a conventional frame of reference may lose its hold unevenly, more thoroughly at one point than another. As a discipline, our own past seems firmly rooted in the seminal contributions of Hempel and Oppenheim (1988), to whom explaining meant the subsumption of what must be accounted for, the explanandum, under a set of laws or a theory. For Hempel and Oppenheim, the univer- 
sality of such laws was seen to be "indispensable" (p. 23). They wrote that theories, as explanatory systems,

have the function of establishing systematic connections among the data of our experience, so as to make possible the derivation of some of those data from others. According as, at the time of the derivation, the derived data are, or are not yet, known to have occurred, the derivation is referred to as explanation or prediction. (Hempel \& Oppenheim, 1988, p. 32)

Explanation, then, appears to be the ultimate aim of theorizing and an integral part of its process. In such a scheme of things prediction and explanation represent two sides of one coin. The former tells the future, the latter accounts for the present and the past. In this "mechanistic" Newtonian framework, time serves as the fourth dimension of space and, as such, strengthens allusions to causality. It no longer flies like an arrow and its irreversibility is gone, a point to be taken up again later in this essay.

From its inception Carl Hempel's "nomological" model has been challenged and amended by philosophers (Salmon, 1984; Van Fraassen, 1980). Social scientists, especially cultural anthropologists, increasingly emphasize "ideographic" or case oriented explanations (cf. Geertz, 1983; Rosaldo, 1993) as a suitable, more realistic alternative. Yet, some of the nomological model's basic tenets continue to reverberate in the family domain, even among those who are moving toward a "postpositivist" approach (Thomas \& Wilcox, 1987). Furthermore, the family field itself has changed over the past decades, intellectually and ideologically (Sprey, 1988). It may be time, therefore, to confront the tensions that remain within the confines of the field's explanatory practice.

My rejection of an exclusive linkage between explanation and theorizing will surface repeatedly throughout the following discussions. I do indeed recognize theory as the prime explanatory vehicle in family studies, but I do not see it necessarily as its most valuable and/or desirable contribution to practitioners or to those who struggle to survive in current marriages and families. Others also have made this point, and Scanzoni and Marsiglio (1993) seemed to extend it to all scholarly explanatory efforts when they observed that "although most of today's researchers are hopeful that their work will have some practical benefit, it is often unclear whether they are asking the kind of research questions that will help supply the most practical answers" (p. 107).
The French sociologist Pierre Bourdieu (1977) contended that people who live in marriages and families function first and foremost as strategists rather than as homespun theoreticians. To survive and prosper, they rely on time-tested pragmatic solutions rather than theories. In a similar vein a contemporary ethnographer wrote:

In everyday life the wise guide themselves as often by waiting to see how events unfold as by plans and predictions. When in doubt, people find out about their worlds by living with ambiguity, uncertainty, or simple lack of knowledge until the clay, if and when it arrives, that their life experiences clarify matters. . . . We often improvise, learn by doing, and make things up as we go along. (Rosaldo, 1993, p. 92)

This is not to suggest that scholarly explanations and practice are incompatible-far from it. It is a reminder, however, that, ultimately, all our explanations are about practice. It seems illusionary, therefore, to consider one's explanatory practice-theoretical or otherwise-as totally separate from the explanatory practice of those one studies. What matters, then, is not the dotted line between the practice of those who ask the questions and that of those to be surveyed, but rather the scholar's preconceptions about any form of contemporary human existence. In his remarkable book, Postmodern Ethics, Zygmunt Bauman (1993) labeled postmodernity as "modernity without illusions" and suggested that such illusions "boil down to the belief that the 'messiness' of the human world is but a temporary and repairable state, sooner or later to be replaced by the orderly and systematic rule of reason" (p. 32). Postmodernity includes an awareness that "the 'messiness' will stay whatever we do or know, that the little orders and 'systems' we carve out in the world are brittle, until further notice, and as arbitrary and in the end contingent as their alternatives" (p. 34). One does not have to share Bauman's image of contemporary social reality to recognize that it exposes as an illusion the conventional dichotomy between the scholarly observer and his or her human subjects.

\section{On Prediction}

Prediction rarely occurs for its own sake but usually happens for a variety of reasons. Many reflect underlying assumptions. This is well illustrated in the following comment by the editor of a multidisciplinary book, Predicting the Future: 
A notion as fundamental as prediction does not exist in a vacuum. It is attached to a variety of other concepts which are linked in a systematic way and constitute part of the very fabric of thought of the society in question. What we mean by prediction is grounded therefore in a set of cultural assumptions about the relationship of the present to the past as well as to the future, about what we take to be knowledge about the world and how we arrive at it. (Howe, 1993, p. 4)

The conventional linkage between the worth of an explanatory statement and its predictive power, for example, reflects cultural assumptions as much as it does rational thought. In our culture, knowledge implies power (cf. Elias, 1984; Foucault, 1980) so that prediction allows for control of the present and the foreseeable future.

Howe's statement also takes us back to the role of time in our explanatory efforts. As a fourth dimension of Newtonian space, the dynamics of time can and traditionally have been dealt with in the framework of four-dimensional geometry. This may be useful in some physical sciences but far less so in the biological and the social sciences. In the words of a prominent mathematician:

Today, general relativity is the direct heir of Newtonian cosmology. The geometrical properties of Einstein's four-dimensional space-time translate into laws of motion. . . . From Newton to Einstein the mathematics has become infinitely more complicated. But the outlook is the same: Time is absorbed into space; the laws of motion become problems in geometry. The universe is closed upon itself, regulated by strict determinism. (Ekeland, 1990, p. 109)

Ekeland observed that recent work in advanced mathematics shows time to be both unpredictable and "innovative" and, as a concept, far closer to the real world than it had appeared to be in Newton's or Einstein's scheme of things:

A simple mathematical model, the baker's transformation, has helped us understand how this notion of time can arise in a purely deterininistic world. ... In this kind of situation the challenge to scientists is very much like that of giving an accurate picture of a stream, with its ever-changing flow, its currents and eddies. (Ekeland, 1990, p. 110)

In that sense, predicting means singling out configurations of events that may or are likely to happen in the future. Time, thought of in this way, enters into the "stream" and becomes part of its flow rather than remaining only a dimension of its external environment. It becomes "a succession of fleeting states, largely independent of each other. The traces of the past disappear very quickly, and each instant of time brings something new". (Ekeland, 1990, p. 111).

What, if anything, does the above have to do with the ways in which family scholars explain phenomena and events? Perhaps a great deal, depending on the degree to which one is willing to challenge the premises that underpin one's approach. The reliance on longitudinal research, for example, rests on the premise that the flow of time is continuous and that the past does not disappear but is causally linked to the present and the future. The theoretical possibility that, over time, systems may lose their "memory" or become effectively separated from it, rarely seems to occur to family scholars. Cross-national comparative research often rests on the premise that an hour's or a day's time is the same all over the world. However, the idea that "fleeting states" of time could be independent of one another poses a major challenge to that assumption.

The fact that 10 years in our past equals 10 years in the future is mathematically correct, but in terms of real time perhaps somewhat misleading. The idea that an 80-year-old person is twice as old as a 40-year-old also seems somewhat unrealistic. Would the average 80-year-old really see himself or herself as halfway to 160 ? By the same token, reaching middle age may mean to some the end, to others a new beginning. Does all this mean, then, that predictability - as a standard-should be eliminated in the evaluation of explanatory worth? Not necessarily. After all, not much of it exists in family studies to begin with. I see predictability as a desirable, risky, and thus limited potential, one that to be worthwhile requires, among other things, a good deal of attention to the context of what is to be foretold and an awareness of what can and cannot be known under any given set of circumstances.

It seems to me that family scholars could benefit from modeling their predictive strategies after those of a field like meteorology. This would mean a focus on the "stream" rather than on just the things that float along in it. It would locate relational or process-oriented concepts, such as "asymmetry" and "turbulence," centrally in one's conceptual scheme. In that manner, it might be easier to grasp the systemic nature of phenomena like violence-prone bonds, fragile networks, or illegitimacy-prone families. On this level of analysis it is not possible to identify which marriages will dissolve or become violent, but this is something many researchers do not wish to predict in the first place. 
The above ideas are far from new. Henri Poincare (1952/1908), the intellectual ancestor of the mathematics of nonlinear systems or chaos theory, wrote in 1908:

Why is it that showers and even storms seem to come by chance, so that many people think it quite natural to pray for rain or fine weather? .. . We see that great disturbances are generally produced in regions where the atmosphere is in unstable equilibrium. The meteorologists see very well that the equilibrium is unstable, that a cyclone will be formed somewhere, but exactly where they are not in a position to say: a tenth of a degree more or less at any given point, and the cyclone will burst here and not there. . . If they had been aware of this tenth of a degree, they could have known it beforehand, but the observations were neither sufficiently comprehensive nor sufficiently precise, and that is the reason why it all seems due to the intervention of chance. (pp. 68-69)

Despite the impressive work of a growing number of contemporary family scholars, especially on the macro-level of analysis, the dynamics of marital and family processes continue to elude all but explanations of a statistical and, therefore, correlational nature. In such explanations, informative as they may be, "chance" continues to play a significant and, perhaps, undeserved part.

\section{Questions and Answers}

In a previous section Adams and Steinmetz (1993) were cited as defining an explanation as providing answers to the questions "how," "why," and "under what conditions." Taking my cue from erotetic logic (Bromberger, 1992), I suggest, however, that all English-language questions initiated with "what," "how," "when," "where," "which," and "who" differ fundamentally from sentences beginning with "why!" The ones in the first set reflect, each in its own way, different premises underlying the exact nature of their answers than is the case for "why" questions. The latter, in contrast to all others, requires "because" answers. "What is this?" thus differs fundamentally from "Why is this the case?"

In this essay, interrogative sentences beginning with "what" or "how" are labeled as either descriptive or conceptual; "under what conditions" simply represents another way of asking "how." "Why" questions are seen as theoretical. All categories of questions are potentially explanatory, but a caveat is in order. In everyday discourse many answers are not expected to ex- plain anything at all. A request for the correct time does not demand any explanation. The distinction made here is an analytical one and is designed to clearly separate different lines of questioning.

Erotetic logic deals with the relationships between questions and answers. Much of its content appears too technical to be of direct use to students of the family. Heuristically, however, its premises and some of its observations should be of interest to anyone involved in the appraisal of our current explanatory practice.

Let me touch briefly on some pertinent ideas. First, as expressed by Bromberger (1992):

Every question stands in three different relations to specifiable propositions. Some propositions give rise to it; some propositions are presupposed by it; some propositions are direct answers to it. For instance, "The Empire State Building is heavy" gives rise to "How heavy ...?" "There is a King of France" is presupposed by "What is the age of the present King of France?" and "The present King .... weighs 500 pounds" is a direct answer to "What is the weight of the present King of France?" (p. 120)

A proposition gives rise to a question if it imposes the condition that a correct answer to it does exist; it is a presupposition for a question if its falsehood means that the question has no correct answer. Ask a foolish question and you get a foolish answer (Belknap \& Steel, 1976).

The notion of a direct answer is a central tenet in erotetic logic. As a response it may be either true or false but it must "completely, but just completely" answer the question (Belknap \& Steel, 1976, p. 3). And, finally, as Belknap and Steel (1976) explained:

The meaning of a question addressed to a query system is not to be identified with how the system processes the query ... but rather it is to be identifled with a range of answers that the question permits That is, for a query system and a user to agree on the meaning of a question is for there to be an agreement as to what counts as an answer to the question, regardless of how, or if, any answer is produced. (p. 2)

If I ask, "Which hat did you wear last night, the blue one or the red one?", I presume that my respondent did wear a hat and that it was either red or blue. The statement "not the red one" may be true but does not answer my question. Other nonanswers are: "I did not wear a hat," "not the blue one," or "I. wore a baseball cap." If the preconditions for a question are not properly met in 
the format of its statement, it becomes spurious because it allows for irrelevant responses.

The presuppositions that underpin "what" and "how" questions differ from those of "why" questions because their descriptive attributes are finite. A "what" question is "canceled when one of its direct answers is confirmed. It is tentatively canceled when one of its direct answers is shown to be probable or warranted" (Bromberger, 1992, p. 121). The same holds for "how" questions.

"Why" questions call for answers that, in turn, may allow for additional questioning. Their "because" responses invoke the presence of forces such as fate, empirical causality, or the power of the supernatural. A question like "What happened here?" can be answered descriptively and conclusively, but "Why did this happen?" allows, in principle, for a seemingly endless chain of further questions.

With this in mind, it is instructive to consider the current state of questioning in family studies. How, for example, does one rate questions that are raised simply because, so far, no one has asked them? What about the questioning that guides so-called exploratory research? Does it produce "exploratory" answers? And how do we evaluate the questioning that underpins our evergrowing data banks? Is it important because of the descriptive quality of its responses? Or is there more to it?

\section{DESCRIPTION}

In family studies, as in all the human sciences, the term description stands for the generation of specific inventories. When one describes, one aims to compile reliable empirical accounts or, as Webster's dictionary has it, "lifelike images" of specific things or events. The usefulness of such stock taking lies in its presumed degree of precision and reliability. It generally is assumed that sound descriptive information may serve as a first step toward further conceptual and/or theoretical reasoning. However, these data alone are not considered explanatory.

\section{Focused Description}

The foregoing may hold for ordinary instrumental stock taking, but it paints an inadequate picture of the role of description in family studies, There, descriptive work tends to be focused and designed to answer specific "what" or "how" questions. The latter are guided by preconceptions about what is to be described.
The sense making of any specific descriptive piece of work depends on its focus. For example, how well does it allow "noise" to be separated from relevant information? How far do its data reach into the future? To give a mundane example, a telephone directory provides reliable information and a degree of predictive power but does not offer valid grounds for conceptual, let alone theoretical, reasoning.

Reliable, descriptive data tend to be seen as objective and, as such, true representations of reality. This is an illusion because objective measures are not intrinsic to the real world. The human-made criteria designed to evaluate designated facts remain in essence arbitrary. To clarify this basic point, assume that we have access to three clearly recognizable images of a given person, namely a photograph, a painted portrait, and a penciled caricature. It makes no sense, then, to ask which one of these best represents the real person. Instead, we choose the one that serves our interest and matches our preconception of what the individual in question "really" is like. As an attribute of description, objectivity at best is a working hypothesis-at worst, a potentially misleading misconception.

Because focused description answers "what" or "how" questions, its explanatory worth depends as much on the quality of its questioning as on the ways in which the responses are obtained. A foolish question begets a foolish answer, regardless of whether it is asked during an in-depth interview or as part of a mailed questionnaire. This may be overlooked when issues of logic are ignored during disputes about the pros and cons of different data-gathering strategies. Consider, for example, the following quote from an otherwise excellent treatise on the art of interviewing:

Even though fixed-question-open-response interviewing may at first appear to be a systematic approach to qualitative interviewing, it is not. It is a different approach entirely. While studies using this approach may avoid some of the vulnerabilities of qualitative interviewing studies, they also lack their strengths. (Weiss, 1994, p. 14)

The voice of logic seems muted throughout this statement. One might ask, for example, what exactly is the strength of "qualitative interviewing"? Is its power superior in the discovery of the truth? If so, which one? The photograph? The painted portrait? Or perhaps the caricature? I assume that scholars who opt for the use of interviews know what they are looking for. But I wonder if they re- 
alize that even the most carefully framed "what" or "how" questions are unlikely to produce valid "because" answers.

To place the above issue in a broader perspective, let me return to mathematics-the most "unreal" of all sciences. In a discussion of Henri Poincaré's contributions to that field one reads:

\begin{abstract}
As a general rule, Poincare, who is without peer where computing is concerned, pushes his calculations as far as they will go. When the limit is reached, he first surveys the road he has covered thus far, and then he tries to peer ahead into the mist. ... At this frontier of knowledge, one must change instruments. For quantitative methods, accurate but limited in scope, we must substitute qualitative methods, which have greater range but less precision. Poincaré was the undisputed master of qualitative methods, which he introduced under the name of analysis situs-nowadays topology. (Ekeland, 1990, p. 35)
\end{abstract}

Poincare was one of the first scholars to stress the limitations of Newton's mecanique celeste and to challenge its deterministic underpinnings, thus opening the door to the study of nonlinear systems or so-called chaos theory.

The choice between a quantitative and a qualitative approach thus involves more than a consideration of the merits of different strategies of data gathering and analysis. Nor can it be equated with a choice between postpositivist and hermeneutic approaches. Rather, it represents a choice between two methodologies in the broadest sense of that term. One of these is, by design, quite accurate but limited in the scope of its "why". questioning. The other aims for greater depth but allows for less precision.

At this stage in the discussion, however, it becomes necessary to consider the potential move of focused description toward the level of theoretical explanation. When this happens, "what" questions make room for "how" questions. In and of themselves, the latter are descriptive, explaining how something works but not telling us why such is the case. "How" questioning, however, may foreshadow theoretical reasoning and, in that capacity, link focused-often conceptualizeddescriptive work to theoretical questioning.

Not surprisingly, the boundaries between descriptive and other explanatory pathways remain disputed. In ethnography, a discipline overlapping family studies, theoretical thinking is discussed as a possible legitimate aspect of field research. For example, Marcus and Fisher (1986) wrote the following:
Within anthropology, ethnographic fieldwork and writing have become the most lively current arenas of theoretical discussion and innovation. Ethnography's concern is with description, and present efforts to make ethnographic writing more sensitive to its broader political, historical, and philosophical implications place anthropology at the vortex of the debate about the problem of representing society in contemporary discourses. (p. vii)

Others, however, see competent descriptive work, because of its line of questioning, as essentially atheoretical (Atkinson, 1990; Hammersley, 1992). I share that view but, as stated earlier, at the same time consider theorizing as only one quite special approach among the spectrum of explanatory strategies.

At the present time, much published research in family studies appears basically descriptive: Its questioning is not designed to reach beyond the "what" or "how." Such work increasingly utilizes large data sets and sophisticated statistical procedures. Its products seem analogous to maps in that they chart unexplored territories and/or update existing inventories. They help identify available routes, but do not tell us where to go. Reliable, up-to-date "maps" of the distribution and course of processes such as marital dissolution, domestic violence, dual career marriages, and mate selection are crucial in ongoing attempts to diagnose the state of and the changes in the realities of contemporary marriage and family living. Given the insights and skills of the scholars involved, they also provide the foundation for deeper questioning.

\section{ConCEPTUALIZATION}

A concept is a definition with a purpose. It usually is created to serve with others of its kind as part of a coherent analytic vocabulary, one that will allow for explanatory thinking. Such conceptual frameworks can be seen as "ways of organizing experience; they are systems of categories that give form to the data of sensation; they are points of view from which individuals, cultures, or periods survey the passing scene" (Davidson, 1984 , p. 183). Apart from providing a necessary condition for theoretical reasoning, such schemes organize our knowledge and may make a kind of sense that reaches deeper and beyond the sense making offered by descriptive maps. In that role, concepts guide but also set a limit to one's potential to observe. One may think about strain, for example, as either mental or physical. This does 
not mean that the two are similar but, rather, that both can be understood as variations on a common theme. John Gottman's (1994) "cascade" model of the divorce process also offers a good illustration. It is a concept born as a metaphor and then recruited to describe the course of a marriage on its way to dissolution.

The foregoing illustrates the explanatory power of conceptual reasoning. Concepts by themselves are not theories, and their explanatory potential differs from that of theories. By the same token, concepts may well become an integral part of theorizing because they provide the vocabulary by means of which "why" questions are formulated.

As a process, conceptualization may evolve from description, but a focused descriptive study also may have been conceptually informed from its outset. In other words, reasoning descriptively and conceptually seems likely to follow a path of reciprocity rather than one of strict linearity. It is quite possible, though, to halt an explanatory march at the conceptual stage. The mere placing of seemingly isolated events in a broader context may be sufficient to meet the needs of given practitioners or of family members trying to make sense of their joint lives. On the frontiers of marital and familial existence, such direct answers may be enough to help manage problems or solve contingencies. So why go on asking?

Eventually, however, isolated concepts, illuminating as they may be, are likely to be linked to others in more or less coherent analytic vocabularies. The concept of minority, for example, tends to be linked with that of power, ethnicity calls forth culture, and so forth. In the history of family studies, Hill and Hansen (1960) were the first to recognize the value of such conceptual frameworks. Their stated aim was not theoretical per se but, rather, to take a "step that raises the inventory beyond simple accumulation toward real significance" (p. 299). That, I suggest, is what conceptualization is all about.

\section{TheOretiCal EXPLANation}

In contrast to the preceding two approaches, theories are expected to answer "why" questions, but many myths and legends also answer these questions. Unique standards have been formulated over the years to distinguish theoretical accounts from folklore, legends, and explanations anchored in the supernatural. These criteria, however, remain arbitrary and open to revision. What theory, myth, and the supernatural do share is their ultimate dependence on faith, on "the evidence of things not seen" (Hebrews 11:1).

Much published work in our field qualifies as theoretical only in a broad sense of the word. After reviewing the 19 theory-focused contributions to the Sourcebook of Family Theories and Methods (Boss, Doherty, LaRossa, Schumm, \& Steinmetz, 1993), I noted that "a telling reminder of the state of our theoretical enterprise is that theorizing, conceptualization, and even description continue ... to mean different things to different scholars in our field" (Sprey, Atkinson, \& Fine, 1993, p. 512). Even theory-oriented papers do not always invoke underlying theoretical assumptions. Their arguments often follow what one prominent scientist (Hoyle, 1994, p. 106) called a "look-see" method. To find out if military combat experience affects the marital careers of veterans, for example, the obvious strategy is to gain access to or create a suitable data set and then find out what the facts are (Gimbel \& Booth, 1994). This approach also allows one to investigate how marital quality, divorce, and remarriage affect the exchange of help between parents and offspring (Amato, Rezac \& Booth, 1995), to see how the rising proportion of unmarried adults impacts on the balance of parent-child exchanges (White \& Peterson, 1995), and so forth.

Such explanatory strategies do not necessarily exclude the use of theory. In fact, one may find certain theoretical considerations cited as the rationale for testable hypotheses or for models to be fitted to the real world. In carrying out the research, some of these theoretical concerns are accepted and others rejected. Those that are rejected do not always feature in the conclusions of such inductive research. They may be discarded and achieve the status of wrong guesses. This is not surprising because answers to "what" and "how" questions are not directly suited to explain why specific working hypotheses turn out to be incorrect.

So one might ask, when can explanatory statements be seen as theoretical? In the context of this essay I would suggest that asking one or more valid "why" questions would be sufficient. But, given the state of knowledge in our field, would it also be necessary? To this question I have no ready response. My inclination is to answer that it depends on the degree to which the "hows" in the explanation not merely allow but actually inspire subsequent "why" questioning. Two brief references to recently published, highquality research may serve to clarify this admittedly disputable point of view. 
In a thorough study of urban-rural differences between patterns of aid giving, Amato (1993) borrowed from social disorganization theory, overload theory, and subculture theory in order to lay the foundations for his questioning. Each of these "mini-theories," however, provided only a limited conceptual vocabulary, so that all three remained precariously integrated into the logical structure of the study's analysis. The formal ties among the three also were left relatively unexplored. In his final summation, the author reported, among other results, that urbanites are somewhat more likely to exchange help with friends than people who live in rural settings and suggested that such "associations appear to exist because the settings have different demographic mixes and because urbanites move more often and live farther from relatives" (p. 261). This sounds reasonable, but seems not directly relevant to any one of the earlier cited theories. The conclusions, then, derive their explanatory worth from their contribution to our empirical knowledge about how friendship ties appear to operate under present-day urban and rural conditions.

A second example, taken from a good study of the linkages between women's occupational and caregiving roles (Moen, Robison, \& Fields, 1994), also provides insight into the dynamics of explanation. The authors of this study wanted to discover if "prolonged caregiving spells preclude women's on-going involvement in a paid job in the same way that caring for preschoolers has" and if "adult caregiving demands hinder women's entry or re-entry into the labor force" (p. S176). They discovered, among other things, that "more recent cohorts of American women are more likely than those born earlier in the century to take on the caregiving role, despite their increased involvement in the paid labor force and the societal revolution in gender expectations" (p. S184).

This finding caused the authors to wonder why caregiving for ailing relatives is still considered to be the province of women (p. S167). Because their study design was informed by a major conceptual frame of reference-that of the life course-such a move toward "why" questioning seems warranted. To respond to this question, however, will require a theoretical perspective in which the dynamics of sociocultural change are of central concern. This means, for instance, asking why sociocultural change, such as that in the prescription of gender roles, may appear inconsistent and even haphazard.
This, in turn, implies a challenge to some or all of the givens that still underpin much theoretical thinking in our field. To illustrate this point, consider a comment by an established ethnographer (Rosaldo, 1993). It addresses a similar issue:

In my view, this gap separating description and conclusion derives from an unresolved tension about whether to describe cultures as loosely tied bundles of informal practices, or as wellformed systems regulated by control mechanisms, or as the interplay of both. (p. 94)

To move from how to why in order to make theoretical sense of seemingly "unruly" findings involves more than a choice between conceptual schemes or even mini-theories. It means coming to grips with the preconceptions that underlie and fashion the ways in which we begin to imagine what it is we wish to explain.

The following two brief quotations from recently published work in the natural sciences should make this clear:

The evolution of a chaotic system is sensitive to the precise specification of the initial state; this means that irrespective of how complex our models become, or how accurate our weather data are, the laws of science impose a limit beyond which prediction of the weather is impossible. (Palmer, 1992, p. 71)

Biological systems, from communities and populations to physiological processes, are governed by nonlinear mechanisms. This means that we must expect to see chaos as often as we see cycles or steadiness. .... . We would all be better off if more people realized that simple nonlinear systems do not necessarily possess simple dynamical properties. (May, 1992, p. 95)

If we conceive of marital and family processes as essentially "nonlinear," we must accept that under certain conditions their cultural interiors indeed may best be thought of as "loosely tied bundles of informal practices" (Rosaldo, 1993, p. 94). Judith Stacey's (1990) book Brave New Families, for example, seems to bear this out. And so does Oscar Lewis' (1966) seminal, much older, study of Puerto Rican families in the "culture of poverty." In the lives of such families, conflict and peace, order and disorder, coexist. The families' mere continuation-sometimes misinterpreted as stability-resembles currents in a river that, despite repeated episodes of flooding and extreme turbulence, still manages to find its way.

Returning for a moment to Moen et al.'s study (1994), there is no theoretical rationale to assume that the continuing changes in and between gen- 
der roles will follow a linear path. Changes reflect a process of "orderly chaos," that is, one quite sensitive to initial states, not necessarily continuous, and thus basically unpredictable.

On the institutional level, a view of process as chaotic may, among other things, help us to see changes in divorce, marriage, and illegitimacy rates as indications of sociocultural "turbulence" and, therefore, as ultimately system maintaining instead of destructive. Changes in these rates may signal a societal process in which institutionalized forms of human sociability compete for a chance to evolve, dominate, or simply survive. Andrew Cherlin's (1992) careful study of the past and current course of marriage, divorce, and remarriage may help illustrate this.

In his chapter on explanations, Cherlin noted that no one foresaw the postwar baby boom, and that, of the explanations of the ups and downs in postwar divorce rates, "most can be classified as either 'period' or 'cohort' ones" (p. 31). This may be of interest to demographers but to me it indicates that such accounts, on the whole, amount to little more than well-reasoned post facto interpretations. Cherlin himself improved on such efforts by framing the course of the postwar decades as "one long-term historical process" and "two specific historical events" (p. 62). He then explained the former as one in which "society-wide changes in women's work lives and reproductive lives have promoted the acceleration of the long-term rise in divorce and the long-term fall in fertility that has characterized the United States since the mid-nineteenth century" (p. 63). The Great Depression and World War II are singled out as the events that interfered with the normal course of long-term historical development. Cherlin's explanation is not theoretical in a neo-positivist sense which, in my view, does not make it less explanatory or "sense making." It does not tell us much about the future course of events. There is no reason to assume, for example, that the next "great depression" will affect the institutions of marriage and family in ways that resemble what happened in the past. One of the main theoretical contributions of family demography seems to be that its findings effectively undermine our faith in the presence of linear causality throughout the course of any long-range sociocultural process.

\section{IN CONCLUSION}

In his autobiography, the astronomer and Nobel Prize recipient Fred Hoyle (1994) remarked that an idea "leads nowhere unless it can be followed up either by an experiment or by a precise calculation" (p. 230). In principle, I agree with him. In our field, we do have ideas but very few mathematical trajectories and, except on the microlevel, no real experimentation to speak of. So where does this leave our explanatory practice? Where it always has been, in our own hands. With this in mind I offer some final comments and close my case.

A crucial problem of explanatory practice in a realm as diverse as ours is for it to achieve both credibility and relevance. To address this, I will again refer to Van Fraassen's book (1980). In a chapter on the pragmatics of explanation, he wrote:

If you ask a scientist to explain something to you, the information he gives you is not different in kind ... from the information he gives you when you ask for a description. .. . To call an explanation scientific is to say nothing about its form or the sort of information adduced, but only that the explanation draws on science to get this information (at least to some extent). (pp. 155-156)

This comment illuminates several issues that were raised throughout this essay:

First, a focused description can be offered as an intentional explanation and, in a proper context, accepted as such. The same is true for conceptual accounts. Because of its unique level of questioning, a theoretical explanation can be either "quantitative" or "qualitative," depending on what the questioner has in mind. As long as the appropriate "why" questions are raised, the selection of a fitting research design remains primarily a technical problem.

This means that on the theoretical level, farreaching choices must be made. Such decisions are not merely rational but also reflect practical and normative issues. As the well-known anthropologist, Clifford Geertz (1983), put it:

The strict separation of theory and data ... the effort to create a formal vocabulary of analysis purged of all subjective reference, the "ideal language" idea; and the claim to moral neutrality... none of these can prosper when explanation. comes to be regarded as a matter of connecting action to its sense rather than behavior to its determinant. The refiguration of social theory represents . . . the sea change in our notion not so much of what knowledge is but of what we want to know. (1983, p. 34) 
The quest for theoretical refiguration implicit in the above is shared by a growing set of scholars in family studies (Gubrium \& Holstein, 1993; Thomas \& Wilcox, 1987). My view on the usefulness of explanatory vocabularies differs from that of Geertz but I do agree that explaining in our field also seems overly concerned with "what knowledge is" at the expense of "what we want to know." Most relevant, however, is the interdependence of these two standards. After all, what we want to know depends on how we decide what knowledge really is. But that decision, in turn, is likely to be influenced by what we, collectively and/or as individuals, consider worth knowing. Let me pursue this important point by means of a final example.

Darwinian evolutionary theory rests on the idea that evolutionary change is blind and an outcome of a continuing interplay between the forces of chance and necessity. The theory lacks the predictive power coveted by positivist scholars, but its explanations manage to place a range of seemingly unconnected facts into understandable configurations. It represents a qualitative or singularity-focused type of explanation, an approach that, parenthetically, is far from exclusively Darwinian. Poincaré's earlier cited analysis situs also is qualitative. In contrast, Newton's equations show both the power and the limitations of deterministic quantitative explanation. They explain the motion of the planets, the cycle of the tides, and the ways in which things fall. They are not of much help, however, in attempts to understand why gravity works the way it does, or with the explanation of climate and the weather.

How, then, will family scholars choose to imagine the realities of marriage and family living? Will they imagine them as analogous to the trajectories of the stars or the everlasting pounding of the tides? Or to the weather or the flow of a river on the way to its ultimate destination? These basic choices cannot be judged as true or false but rather as useful or useless. The relevance of the choice to those who decide is contextual and, as such, reflects the aspirations, knowledge, and history of those who raise the questions. For some of us the choice will be part of a search for God's truth, for others knowledge as a step towards liberation, and, perhaps for a few, the outcome of an insatiable curiosity. To label any of such preferences as either wrong or correct would be, especially in a discipline like ours, unrealistic and counter-productive.

\section{NoTE}

This article is a thoroughly revised and expanded version of a paper presented at the Theory and Methodology Workshop of the annual meeting of the National Council on Family Relations in Minneapolis, Minnesota, November 1994.

\section{REFERENCES}

Adams, B. N., \& Steinmetz, S. K. (1993). Family theory and methods in the classics. In P. G. Boss, W. J. Doherty, R. LaRossa, W. R. Schumm, \& S. K. Steinmetz (Eds.), Sourcebook of family theories and methods (pp. 71-95). New York: Plenum.

Amato, P. R. (1993). Urban-rural differences in helping friends and family members. Social Psychology Quarterly, 56, 249-261.

Amato, P. R., Rezac, S. J., \& Booth, A. (1995). Helping between parents and young adult offspring: The role of parental marital quality, divorce, and remarriage. Journal of Marriage and the Family, 57, 363-374.

Atkinson, P. (1990). The ethnographic imagination. New York: Routledge.

Bauman, Z. (1993). Postmodern ethics. Oxford, UK: Blackwell.

Belnap, N. D., Jr., \& Steel, T. B., Jr. (1976). The logic of questions and answers. New Haven, CT: Yale University Press.

Boss, P. G., Doherty, W. J., LaRossa, R., Schumm, W. R., \& Steinmetz, S. K. (Eds.). (1993). Sourcebook of family theories and methods: A contextual approach. New York: Plenum.

Bourdieu, P. (1977). Outline of a theory of practice. New York: Cambridge University Press.

Bridgman, P. W. (1928). The logic of modern physics. New York: MacMillan.

Bromberger, S. (1992). On what we know we don't know. Chicago, IL: University of Chicago Press.

Cherlin, A. J. (1992). Marriage, divorce, remarriage. (rev. ed.). Cambridge, MA: Harvard University Press.

Davidson, D. (1984). Inquiries into truth and interpretation. New York: Clarendon Press.

Ekeland, I. (1990). Mathematics and the unexpected. Chicago, IL: University of Chicago Press.

Elias, N. (1984). Knowledge and power. In N. Stehr \& V. Meja (Eds.), Society and knowledge (pp. 251-264). New Brunswick, NJ: Transaction.

Foucault, M. (1980). Power/knowledge: Selected interviews and other writings 1972-1977. New York: Pantheon Books.

Gallie, W. B. (1968). Philosophy and the historical understanding (2nd ed.). New York: Schocken Books.

Geertz, G. (1983). Local knowledge: Further essays in interpretative anthropology. New York: Basic Books.

Gimbel, C., \& Booth, A. (1994). Why does military combat experience adversely affect marital relations? Journal of Marriage and the Family, 56, 691-703.

Gottman, J. M. (1994). What predicts divorce? Hillsdale, NJ: Lawrence Erlbaum.

Gubrium, J. F., \& Holstein, J. A. (1993). Phenomenology, ethnomethodology, and family discourse. In P. G. Boss, W. J. Doherty, R. LaRossa, W. R. Schumm, \& S. K. Steinmetz (Eds.), Sourcebook of family theories and methods: A contextual approach (pp. 651-672). New York: Plenum. 
Hammersley, M. (1992). What's wrong with ethnography? New York: Routledge.

Hempel, C. G., \& Oppenheim, P. (1988). Studies in the logic of explanation. In J. C. Pitt (Ed.), Theories of explanation (pp. 9-50). New York: Oxford University Press.

Hill, R., \& Hansen, D. (1960). The identification of conceptual frameworks utilized in family study. Joumal of Marriage and the Family, 22, 299-311.

Howe, L. (1993). Introduction: Predicting the future. In L. Howe \& A. Wain (Eds.), Predicting the future (pp. 1-7). New York: Cambridge University Press.

Hoyle, F. (1994). Home is where the wind blows: Chapters from a cosmologist's life. Mill Valley, CA: University Science Books.

Kellert, S. K. (1993). In the wake of chaos: Unpredictable order in dynamical systems. Chicago, IL: University of Chicago Press.

Lewis, O. (1966). La vida: A Puerto Rican family in the culture of poverty. New York: Random House.

Marcus, G., \& Fisher, M. M. J. (1986). Anthropology as cultural critique. Chicago, IL: University of Chicago Press.

May, R. (1992). The chaotic rhythms of life. In N. Hall (Ed.), The new scientist guide to chaos (pp. 82-95). London, England: Penguin Books.

Moen, P., Robison, J., \& Fields, V. (1994). Women's work and caregiving roles: A life course approach. Journal of Gerontology, 49, 176-186.

Palmer, T. (1992). A weather eye on unpredictability. In $\mathrm{N}$. Hall (Ed.), The new scientist guide to chaos (pp. 69-81). London, England: Penguin Books.

Poincaré, H. (1952). Science and method. Translated by F. Maitland. New York: Dover. (Original work published 1908)

Rosaldo, R. (1993). Culture and truth. Boston, MA: Beacon Press.

Salmon, W. C. (1984). Scientific explanation and the causal structure of the world. Princeton, NJ: Princeton University Press.

Scanzoni, J., \& Marsiglio, W. (1993). New action theory and contemporary families. Journal of Family Issues, $14,105-132$.

Sprey, J. (1988). Current theorizing on the family: An appraisal. Journal of Marriage and the Family, 50, 875-890.

Sprey, J. (1990). Theoretical practice in family studies. In J. Sprey (Ed.), Fashioning family theory (pp. 933). Newbury Park, CA: Sage.

Sprey, J., Atkinson, M. P., \& Fine, M. A. (1993). Review of Sourcebook of family theories and methods: A contextual approach. Journal of Marriage and the Family, 56, 511-515.

Stacey, J. (1990). Brave new families. New York: Basic Books.

Szinovacz, M. (1987). Family power. In M. B. Sussman \& S. K. Steinmetz (Eds.), Handbook of marriage and the family (pp. 651-693). New York: Plenum.

Thomas, D. L., \& Wilcox, J. E. (1987). The rise of family theory: A historical and critical analysis. In M. B. Sussman \& S. K. Steinmetz (Eds.), Handbook of marriage and the family. (pp. 81-102). New York: Plenum.

Van Fraassen, B. (1980). The scientific image. New York: Clarendon Press.
Weiss, R. S. (1994). Learning from strangers. The art and method of qualitative interview studies. New York: Free Press.

White, L., \& Peterson, D. (1995). The retreat from marriage: Its effect on unmarried children's exchange with parents. Journal of Marriage and the Family, 57, 428-434. 